\section{Screening of antibiotic residue in poultry in Kathmandu valley of Nepal: A cross-sectional study}

\author{
Rajiv Sapkota ${ }^{1 *}$, Ramila Raut ${ }^{1}$, Sujan Khanal' ${ }^{1}$ Muna Gyawali ${ }^{1}$ and \\ Dipesh Sahi
}

${ }^{1}$ Trichandra Multiple College, Kathmandu, Nepal

${ }^{2}$ SANN International College, Kathmandu, Nepal

\begin{abstract}
This cross-sectional study was conducted to screen the presence of antibiotic residue in poultry. A total of 60 samples (30 Muscle and 30 Liver) were taken from local meat shops from different parts of Kathmandu valley. Disc assay method was used. Escherichia coli (ATCC 25922) and Staphylococcus aureus (ATCC 25923) were used as test organisms. The results revealed 8 positive samples (which is $13 \%$ ). Among 30 Liver samples, 3 showed positive result, while only 2 muscle sample indicated positive result. Muscle has the highest percentage of positive results than liver. For $S$. aureus showed greater percentage of positive results than that of $E$. coli. The presence of antibiotic residue and its many pathological effects to public health demands the strict rules and regulations as well as surveillance from the concerned authorities.
\end{abstract}

\section{More Information}

*Address for Correspondence: Rajiv Sapkota, Trichandra Multiple College, Kathmandu, Nepal, Tel: +9779849697624; Email: rajivgerbeck@gmail.com

Submitted: 18 September 2019

Approved: 26 September 2019

Published: 27 September 2019

How to cite this article: Sapkota R, Raut R, Khanal S, Gyawali M, Sahi D. Screening of antibiotic residue in poultry in Kathmandu valley of Nepal: A cross-sectional study. Arch Pharm Pharma Sci. 2019; 3: 079-081.

DOI: dx.doi.org/10.29328/journal.apps.1001017

Copyright: (c) 2019 Sapkota R, et al. This is an open access article distributed under the Creative Commons Attribution License, which permits unrestricted use, distribution, and reproduction in any medium, provided the original work is properly cited.

Keywords: Antibiotic residue; Poultry tissues; Disc assay; Public health; Kathmandu valley

W) Check for updates

\section{Introduction}

SAWaksaman, a Nobellaureate defined the termantibiotics as those substances which are produced by synthesis of living microorganism and are toxic for another [1].

The antibiotics these days are often used for enhanced growth especially in broilers and flattener [2]. To promote growth and for productivity purposes, antibiotics are given periodically during the lifetime of the broilers. Application of antibiotics in the prevention and treatment of bacterial disease in livestock production is an almost same manner to those used in human medicine but with a tenuous difference [3].

There is an immediate warning on the potential effects on public health unless government regulates and implement on the use of antimicrobials [be it antibiotics, or antiviral or anti parasites] [4]. Antibiotics used in food animals can affect the public health due to their secretion in the tissues which are edible and are usually found in trace amounts and they are generally called as residue. Such residue such as Oxytetracycline and Eurofloxacin which have been detected above the maximum residue level (MRL) in chicken tissues [5].

Some pathological effects produced by antibiotic residue in food are: Transfer of antibiotic-resistant bacteria in a human, Immunopathological effects, Carcinogenicity [sulphamethazine, oxytetracycline, furazolidone], Mutagenicity, Nephrotoxicity, Reproductive disorders, bone marrowtoxicity [chloramphenicol] and Allergy [penicillin] [2].

The malpractice of antibiotics use can increase and select the multi-resistant of pathogenic strains bacteria, which can be transferred to human via food [6]. A significant question of risk is the large pools of genes in meat animals due to the use of broad-spectrum antibiotics as a food additive. The threat of the ineffectiveness of antibiotic even to treat simple infections remains imminent unless we intervene in the use antibiotics let alone broad-spectrum antibiotics.

There is rampant use of drugs in spite of the problem connected with drug residues, which may eventually become a part of the human diet [7].

Improper use or limited withdrawal period of the antimicrobial drugs may leave drug residue in the systems of food-producing animals which are edible. Antibiotic growth promoters are found to suppress the gut bacteria which leaves more nutrients for chickens to be absorbed [8]. Many studies in the recent years have shown that the antibiotics that have been given to poultry and livestock production were deposited in liver, kidney, muscle and bones surpassing maximum Residue Limit [9]. 
As a result of modern and advanced methods for efficient chicken production, diseases have been widespread. The prevalent diseases for examples typhoid, Mycotoxicosis, E. coli infections, coccidiosis, Salmonellosis, enteritis, ascites, Newcastle disease etc. not only affect poultry growth and production but also be the factor for the economic losses due to high mortality among the flocks. [7]. The presence of residue from veterinary medicinal products in foods of animal origin could jeopardize international trade [10].

In Nepal, majority of drugs are used without any hindrances whatsoever in a lump sum amount and upkeep of withdrawal period and evaluation of residue in meat and milks are not effectively tracked by government and private sectors [11].

For a detection of residue of pharmacologically active substances in food-producing animals and their animal products, microbiological inhibition tests (MIT) are used all over the world. It is based on the principle on the inhibition of growth of test organisms which are sensitive to antibiotics and sulphonamides.

There are various methods which are applied to detect the presence of residue. Here we applied the Disc assay method, because of their cost effectively and in contrast to, for example immunological or receptor- based tests, they have the capacity to cover the whole antibiotic spectrum within a single test [12].

\section{Materials and Methods}

\section{Study site}

A total of 60 meatsamples (liver and muscles) were collected from local meat shops of different areas of Kathmandu valley namely Kalanki, Balaju, Budhanilkantha, Pepsicola, Chabahil, Tinkune, Bagbazar, Satdobato and Jadibuti and processing was done in Miron Laboratory and Research center (MRLC), Kathmandu, Nepal. These are the places where meat is consumed in huge quantities inside the Kathmandu valley.

\section{Test organism}

Escherichia coli (ATCC 25922) and Staphylococcus aureus (ATCC 25923) were used as test organisms. The test organisms were obtained from the National public health laboratory (NPHL), Teku, Nepal.

\section{Sample collection}

$5 \mathrm{gm}$ of chicken meat and liver samples were weighed and collected from each meat shop in a sterile polythene bags and sealed properly. Probability of contamination was minimized by wearing gloves and masks. The sample was transported in an ice bag to the laboratory soon after collection. The samples were kept in a freezer thereafter for experimental purpose.

\section{Preparation of the disc}

Paper discs were prepared by cutting the filter paper (Whatmann No.1) to the size of approximately $4 \mathrm{~mm}$ in diameter and were sterilized.

\section{Disc assay method}

Sterilized nutrient agar plates were inoculated with a loop of freshly prepared suspension of each bacterial sample (for the lawn culture). An incision was made in each tissue sample. Then, using sterile forceps, a sterile paper disc was placed and left for few minutes until it was soaked, followed by the transfer of disc to the agar surface. Then the plates were inverted and incubated at $37^{\circ} \mathrm{C}$ for 24 hours.

\section{Results and Discussion}

Out of 60 samples, 8 samples were found to be positive (five muscle and three liver) and 52 samples were found to be negative.

For Staphylococcus aureus three samples each of Muscle and Liver were found positive. For E. Coli only two samples of Muscle showed positive result (Tables 1,2).

A similar study done in Kavre and Kailali districts of Nepal by using Kit Test method, $22 \%$ of the samples were found positive [13]. Our results were significantly lower than some of similar studies; $40 \%$ [14] and 27\% [15]. The differences in results could be due to various reasons. The use of different bacteria as test organism and their susceptibility to different antibiotic, due to the inconsistencies in sample size, variation of practice of antibiotic use in different locations, difference in the methods for detection (here we used Disc assay method).

This study clearly showed there was the presence of antibiotic residue in the sampled poultry tissue. It was found that $13 \%$ of 60 samples were found to be positive and $87 \%$ were found to be negative. Out of 8 positive tissue samples 5 muscles samples and 3 liver samples were found positive. Both Muscle and Liver were found positive while using Staphylococcus aureus (ATCC 25923) as test bacteria but only muscle samples were found to be positive while using Escherichia coli (ATCC 25922) as test bacteria.

The positive sample perhaps could be due to the fact that farmers are unknown about the withdrawal period. They are encouraged and sometimes compelled to sell their chickens for their economic benefits and competitive market. Residues could be deposited when antibiotic achieved high tissue penetrability and absorbed promptly from gastrointestinal

\begin{tabular}{|c|c|c|c|}
\hline \multicolumn{4}{|c|}{ Presence of antibiotic residue (Muscle Samples) } \\
\hline \multicolumn{2}{|c|}{ S. aureus } & \multicolumn{2}{|c|}{ E. Coli } \\
\hline Negative & Positive & Negative & Positive \\
\hline 27 & 3 & 28 & 2 \\
\hline
\end{tabular}

Table 2: Number of positive and negative samples in Liver samples.

\begin{tabular}{|c|c|c|c|}
\hline \multicolumn{3}{|c|}{ Presence of antibiotic residue (Liver Samples) } \\
\hline \multicolumn{2}{|c|}{ S. aureus } & \multicolumn{2}{c|}{ E. Coli } \\
\hline Negative & Positive & Negative & Positive \\
\hline 27 & 3 & 30 & 0 \\
\hline
\end{tabular}


tract of chickens. Yet, Nutritional source, occurrence of bivalent ions in the gut and physiochemical properties of the drug may influence absorption from the digestive tract [5]. Proper governmental regulations, monitoring and awareness related to the poultry raising and meat consumption among the public is warranted in the future.

\section{Acknowledgements}

We are indebted to Dr. Koirala, Dr. KRIBB Founder for his continuous support and encouragements for this research and publications.

\section{References}

1. Ezenduka EV, Oboegbulem SI, Nwanta JA. Rapid detection of antimicrobial residues in poultry: A consequence of non-prudent use of antimicrobials. Health. 2014; 6: 149-152.

2. Nisha AR. Antibiotic Residue- A Global Hazard. Veterinary World. 2008; 1: 375-377.

3. Health AP. Antibiotic Use in Animal Agriculture Is Safe and Necessary. 2011; 531-541.

4. Wise R. Antimicrobial resistance: Priorities for action. J Antimicrob Chemother. 2002; 49: 585-586.

PubMed: https://www.ncbi.nlm.nih.gov/pubmed/11909829

5. Karmi M. Detection and presumptive identification of antibiotic residues in poultry meat by using FPT. Global J Pharmacol. 2014; 8: 160-165.

6. Hakem A, Titouche Y, Houali K, Yabrir B, Malki O, et al. Screening of
Antibiotics Residues in Poultry Meat by Microbiological Methods. J Chemical Information and Modeling. 2013; 53: 1689-1699.

7. Mund MD, Khan UH, Tahir U, Mustafa BE, Fayyaz A. Antimicrobial drug residues in poultry products and implications on public health: $A$ review. Int J Food Properties. 2017; 20: 1433-1446.

8. Veterinarian GG. Assessment of Some Antibiotics Residues in Broiler. 2018.

9. Sarker YA, Hasan MM, Paul TK, Rashid SZ, Alam MN, et al. Screening of antibiotic residues in chicken meat in Bangladesh by thin layer chromatography. J Adva Vet Animal Res. 2018; 5.

10. Tadesse T, Tadesse T. Public Health Impacts of Antibiotic Residues in Foods of Animal Origin: A Review. 2017; 7: 6-11.

11. Thapaliya M, Karki TB, Sedai D. Sulfonamides and Penicillin Residue in Market Milk. 2013; 8: 60-64.

12. Pikkemaat MG. Microbial screening methods for detection of antibiotic residues in slaughter animals. Analytical and Bioanalytical Chemistry. 2009; 395: 893-905.

PubMed: https://www.ncbi.nlm.nih.gov/pubmed/19484227

13. Raut R, Mandal RK, Kaphle K, Pant D, Nepali S, et al. Assessment of Antibiotic Residues in the Marketed Meat of Kailali and Kavre of Nepal. International J Applied Sci Biotechnol. 2017; 5: 386.

14. Ezenduka EV, Oboegbulem SI, Nwanta JA. Rapid detection of antimicrobial residues in poultry: A consequence of non-prudent use of antimicrobials. Health. 2014; 6: 149-152.

15. Elnasri A, Salman M, Rade SA, El Mohammed, Kolo B, Geidam, YA, et al. Screening of Antibiotic Residues in Poultry Liver, Kidney and Muscle in Khartoum State, Sudan Sample collection. Bas J Vet Res. 2014; 14: 43-51. 